varying interests, but with the common object of producing a man of sound judgement and reasonable technical competence who has the courage to criticise his own as well as other people's work.

There is today much emphasis on surgical technique and too little on the humanistic approach to orthopaedic surgery, for without it we are nothing more than craftsmen. We could not do better in this, the fiftieth year of our Association, than to remember the teaching of the founders of our speciality for whom the social aspects of disease and injury were of paramount importance. In the words of Robert Jones, until an individual interest is taken in a man, from his entrance into hospital until he enters civil life, our material duty will have been left undone.

Roland BarNes.

I acknowledge gratefully the help I have received from Mr F. G. St Clair Strange, who contributed the section on Travelling Fellowships. I have also consulted and quoted from The Life of Robert Jones by Frederick Watson, Sir Harry Platt's First “"Founder's Lecture," Rocyn Jones's Presidential Address to the Royal Society of Medicine, H. Osmond-Clarke's article on " Half a Century of Orthopaedic Progress in Great Britain," and the first Minute book of the British Orthopaedic Association.

\title{
ACRYLIC BONE CEMENT-BOND OR PLUG?
}

Themistocles Gluck, in his lectures to the German Surgical Society and the Berlin Medical Society during the summer of 1890 , described the use of ivory ball-and-socket joints, especially suitable for the treatment of disease of the hip joint: they were stabilised in the bone with a cement composed of colophony, pumice powder and plaster. He said that the cement remained walled off in the marrow cavity in the same way as a bullet, the marrow cavity appearing to have almost unlimited tolerance to aseptic implantation.

In 1951 Haboush used a self-curing acrylic dental cement to secure a total hip replacement (Haboush 1953). Also at this time similar resins were being used to repair defects in the skull after brain surgery. Between 1952 and 1957 Henrichsen, Jansen and Krogh-Poulsen (1952), Spence (1954), and Wiltse, Hall and Stenehjem (1957) reported favourably on the use of cold-curing acrylic polymers in contact with bone. Adverse reports on the use of these polymers in contact with tissues have been few. Spealman, Main, Haag and Larson (1945) observed in mice that on inhalation, the monomer vapour - the liquid part of the acrylic cement system-was more toxic than acetone. In patch tests on medical students they found that approximately 30 per cent developed mild erythema at the site of application of the monomer and that ten days later 20 per cent of those patch-tested showed evidence of sensitisation. Kramer and McLean (1952) reported that with certain cold-curing acrylic dental filling materials used in unlined cavities in teeth there was an acute inflammatory reaction, but no permanent damage was caused to the pulp. Others believe that free monomer can cause acute hyperaemia and kill the pulp. Oppenheimer, Oppenheimer, Danishefsky, Stout and Eirich (1955) reported that when polymethylmethacrylate tagged with $\mathrm{C}^{14}$ was implanted in the tissues of rats, the labelled carbon could be detected in the urine after fifty-four weeks. They deduced that the polymer broke down in the tissues but the amount of monomer released was minute and was rapidly eliminated in the urine.

In Britain in the last six years two products, Simplex $\mathrm{P}$ and $\mathrm{C}^{*}$ and $\mathrm{CMW}$ Bone Cement $\dagger$ have been used in several thousand patients. The monomer contains an inhibitor, hydroquinone and a system activator, dimethyl-para-toluidine. The polymer powder contains a peroxide catalyst. At the Royal National Orthopaedic Hospital, where extensive bone replacements with prostheses have been carried out, upwards of 100 grammes of polymer, combined with 50 millilitres of monomer, have been used. In a few cases in which total hip replacements have

* Manufactured by Dental Fillings Limited, London.

† Manufactured by CMW Laboratories Limited, Blackpool. 
needed revision, an operation involving insertion of cement has been repeated after an interval and there have been no apparent ill effects. The writer is not aware of any proven cases in orthopaedic surgery of physiological change or undesirable tissue reaction attributable to the chemical constituents of the resin systems. There is no evidence that monomethyl or polymethylmethacrylate or other constituents of Simplex and CMW bone cements can induce a malignant change in human tissues.

The polymerisation of self-curing acrylic cements is an exothermic reaction, the number of calories produced being proportional to the mass of resin used. The rise in temperature at the bone/resin interface, besides depending on the mass of resin, is also influenced by the ratio of mass of metal-which can absorb heat-to the mass of resin. Thermocouple measurements have shown that the temperature at various sites in the same patient can vary between 40 degrees and 60 degrees Centigrade. The extent of the tissue damage in each case is therefore difficult to predict. It must also be remembered that in the course of polymerisation the resin mass shrinks in volume.

In this issue of the Journal a paper by Charnley, Follacci and Hammond on the long-term reaction of bone to self-curing acrylic cement is further confirmation of the apparent acceptance by the tissues of self-curing resins of the CMW and Simplex type. While it is well known that Charnley is reporting on the use of CMW bone cement, it is to be hoped that future authors will give the composition of the materials they are using.

Charnley and colleagues state that the bone has remained radiologically normal in 81 per cent of their cases, implying that in 19 per cent it has not. Perhaps 1 per cent might be ascribed to undiagnosed infection; but this still leaves 18 per cent of cases in which there are unexplained radiological changes. It is said that the spindle-shaped thickening of the femoral shaft in relation to the distal end of the stem of the prosthesis is the physiological response to an increased concentration of local stress arising at the transition from the normal flexible shaft of the femur to a part made more rigid by the cement and the prosthesis. But what is the mechanism? Haboush (1953) has calculated that at the tip of an Austin Moore prosthesis, used without cement, the stress in the lateral cortex of the femur may be as much as 202.5 kilograms per square centimetre (3,500 p.s.i.). Cement modifies the shape of the intramedullary stem to fit the form of the bony cavity. The prosthesis will be securely locked in position only if the cavity is suitably prepared and the load per unit area on the bone is thereby reduced to an acceptable level. The correct distribution of the forces acting through the stem of the prosthesis can be achieved only if the cavity is fully packed with resin and the cavity wall is of viable bone which will not be resorbed after operation.

In the preparation of the cavity the use of a tapered rasp or reamer, which crushes trabecular bone and drives marrow into the interstices, may provide an insecure foundation for the acrylic resin that is either resorbed or further collapses. It is advisable therefore to remove all debris from the walls of the cavity with a sharp spoon. When the cavity is being packed, blood and air must not be trapped. This may be avoided by the insertion of a small-bore plastic tube into the marrow cavity for a distance at least equal to the length of the femoral stem of the prosthesis. When the medullary cavity has been fully packed by "thumbing in " the resin, and air and blood have escaped through the lumen of the tube, the tube is withdrawn. In cases of massive bone replacement in which the cement may have to be introduced for a considerable distance along the shaft of the bone, a less viscous mix, injected by means of a mechanically or pneumatically operated gun, may be used. Prostheses must be introduced when the viscosity of the resin is such that it will not well out of the marrow cavity but rather be driven by the wedge action of the stem into the bony interstices.

Even when all the precautions to obtain complete filling of the marrow cavity are taken, we must face the fact that the stem of the prosthesis now composed of metal plus encrusting acrylic will still not be united to the bone, but will be supported by resilient fibrous tissue which will permit movement of the acrylic resin relative to the bone when load is applied to the

VOL. 50 B, NO. 4, NOVEMBER 1968 
implant. The amount of fibrous tissue will determine the extent of the movement of the prosthesis. Differential movement between the resin and the bone will result in changes in pressure in the tissues which must be reflected in changes of intracapillary pressure. This may lead to a change in volume of extravascular fluid, followed by further fibrous tissue formation and resorption of bone. Perhaps the hypertrophy of the femoral cortex is caused by changes in the haemodynamics of the cortical blood flow occasioned by the piston action of the prosthesis in the marrow cavity. Perhaps the deep pain in the upper anterior and lateral thigh seen in most cases of loose prosthesis is caused by a change in pressure transmitted to subperiosteal nerve endings.

Charnley's good results confirm the efficacy of his method of preparing the cavity and packing it with CMW bone cement. His paper is a tribute to the foresight of Themistocles Gluck.

JOHN T. SCALES

\section{REFERENCES}

Gluck, Th. (1891): Referat über die durch das moderne chirurgische Experiment gewonnenen positiven Resultate, betreffend die Naht und den Ersatz von Defecten höherer Gewebe, sowie über die Verwerthung resorbirbarer und lebendiger Tampons in der Chirurgie. Archiv für klinische Chirurgie, 41, 187.

Haвoush, E. J. (1953): A New Operation for Arthroplasty of the Hip based on Biomechanics, Photoelasticity, Fast-setting Dental Acrylic, and Other Considerations. Bulletin of the Hospital for Joint Diseases, 14, 242.

Henrichsen, E., Jansen, K., and Krogh-Poulsen, W. (1952): Experimental Investigation of the Tissue Reaction to Acrylic Plastics. Acta Orthopaedica Scandinavica, 22, 141.

Kramer, I. R. H., and McLean, J. W. (1952): The Response of the Human Pulp to Self-polymerising Acrylic Restorations. British Dental Journal, 92, 255; $281 ; 311$.

Oppenheimer, B. S., Oppenheimer, E. T., Danishersky, I., Stout, A. P., and Eirich, F. R. (1955): Further Studies of Polymers as Carcinogenic Agents in Animals. Cancer Research, 15, 333.

Spealman, C. R., Main, R. J., HaAg, H. B., and Larson, P.S. (1945): Monomeric Methyl Methacrylate: Studies on Toxicity. Industrial Medicine, 14, 292.

SPENCE, W. T. (1954): Form-fitting Plastic Cranioplasty. Journal of Neurosurgery, 11, 219.

Wiltse, L. L., Hall, R. H., and Stenehjem, J. C. (1957): Experimental Studies Regarding the Possible Use of Self-curing Acrylic in Orthopaedic Surgery. Journal of Bone and Joint Surgery, 39-A, 961. 